\title{
Análise de metais pesados no Sistema Aquífero Bauru em Mato Grosso do Sul
}

\author{
Analysis of heavy metals in the Bauru Aquifer System in Mato Grosso do Sul
}

\author{
Denise Aguena Uechi', Sandra Garcia Gabas², Giancarlo Lastoria ${ }^{3}$
}

口

\begin{abstract}
RESUMO
Os metais pesados são contaminantes de grande preocupação ao atingirem os aquiferos, devido à sua toxicidade em determinadas concentrações e a sua difícil remediação. Esteestudo visou analisar as concentrações de cobre(Cu), cromo (Cr), ferro (Fe), manganês (Mn) e zinco (Zn) presentes no Sistema Aquífero Bauru (SAB), no Estado de Mato Grosso do Sul, no período de 2009 a 2013. Os teores de $\mathrm{Cu}, \mathrm{Cr}$ eZn mantiveram-se dentro dos limites de potabilidade estabelecidos na legislação brasileira, ao contrário do Mn e do Fe. Há, na área de afloramento do Aquífero. Atividades econômicas podem influenciar na qualidade das águas subterrâneas, como, por exemplo, o uso da vinhaça na fertirrigação na cultura de cana-deaçúcar e o curtimento mineral do couro. Este estudo teve o objetivo de reforçar a importância da consolidação de uma rede de monitoramento da qualidade das águas subterrâneas, a fim de estabelecer um zoneamento de vulnerabilidade à poluição por meio de medidas de controle, prevenção e remediação.
\end{abstract}

Palavras-chave: metais pesados; aquífero livre; contaminação; água potável.

\begin{abstract}
Heavy metals are contaminants of great concern in the aquifers due to their toxicity at certain concentration and difficult remediation. This study aimed to analyze the concentrations of $\mathrm{Cu}, \mathrm{Cr}$, Fe, Mn and $\mathrm{Zn}$ present in Bauru Aquifer System in Mato Grosso do Sul State, from 2009 to 2013. The content of $\mathrm{Cu}, \mathrm{Cr}$ and $\mathrm{Zn}$ were within the limits of drinking water from Brazilian legislation, unlike Mn and Fe. The use of vinasse in fertigation of sugar cane cultivation and mineral tanning leather can influence the quality of groundwater in the outcropping area of the aquifer. This study reinforces the importance of monitoring groundwater quality in order to establish a zoning of vulnerability to pollution through control measures, prevention and remediation.
\end{abstract}

Keywords: heavy metals; free aquifer; contamination; drinking water.

\section{INTRODUÇÃO}

A explotação deáguas subterrâneas no país e no mundo vem assumindo grandes proporções por inúmeras vantagens, dentre elas, a qualidade da água, os custos de exploração e a redução das fases de tratamento até o consumidor final. Contudo, o aumento da industrialização, da urbanização e da população tem gerado problemas na explotação das águas subterrâneas, que muitas vezes ocorre de maneira desenfreada e sem controle, colocando em risco a saúde da própria população e do meio ambiente devido, à vulnerabilidade natural dos aquíferos e ao gerenciamento inadequado das atividades antrópicas.

É comum a grande preocupação com as áreas de recarga dos aquíferos em relação a contaminações, principalmente por metais pesados. Isso acontece pois, em áreas de afloramento, como no caso dos aquíferos porosos (por exemplo, o Sistema Aquífero Bauru - SAB), as condições hidráulicas favorecem a infiltração, mesmo considerando que nem toda área de afloramento é necessariamente área de recarga (GOVERNO DO ESTADO DE MATO GROSSO DO SUL, 2010). A contaminação de aquíferos por metais pesados é um problema mundial por serem de difícil remediação e não serem biodegradáveis (BAILEY, 1999). Assim, tornam-se elementos de grande preocupação, pois em elevadas concentrações podem provocar efeitos tóxicos sobre organismos vivos podendo até ocasionar a morte. No entanto, alguns desses metais, quando em baixas concentrações, são considerados micronutrientes essenciais para os seres vivos, tornando-se tóxicos quando ultrapassam determinados valores (WHO, 2011).

Embora o SAB, em Mato Grosso do Sul, seja um importante manancial para abastecimento de água, garantindo a maior vazão média retirada entre todos os aquíferos explotados no Estado (GOVERNO DO ESTADO DE MATO GROSSO DO SUL, 2010), inexistem estudos hidrogeológicos e hidroquímicos sobre esse aquífero.

'Doutoranda em Tecnologias Ambientais pela Universidade Federal de Mato Grosso do Sul (UFMS) - Campo Grande (MS), Brasil.

²Doutora em Engenharia Civil pela Universidade de São Paulo (USP) - Campo Grande (MS), Brasil.

${ }^{3}$ Doutor em Geociências e Meio Ambiente pela Universidade Estadual Paulista Júlio de Mesquita Filho (UNESP) - Campo Grande (MS), Brasil.

Endereço para correspondência: Sandra Garcia Gabas - Programa de Pós-Graduação em Tecnologias Ambientais da Faculdade de Engenharias, Arquitetura e Geografia da Universidade Federal de Mato Grosso do Sul - Cidade Universitária, s/n - Caixa Postal 549 - 79070-900 - Campo Grande (MS), Brasil - E-mail: sandra.gabas@gmail.com Recebido: 03/11/14 - Aceito: 24/05/16 - Reg. ABES: 142430 
O Estado de Mato Grosso do Sul é uma das maiores economias agrícolas do Brasil, predominando extensas culturas de cana-de-açúcar, soja, milho, pastagens e áreas de silvicultura para produção de celulose e papel, o que torna indispensável o uso de fertilizantes e agroquímicos para o controle de pragas. Geralmente, os fertilizantes minerais contêm traços de impurezas - entre as quais se destaca a presença de metais pesados, como o $\mathrm{Cu}$ e o $\mathrm{Zn}$ (OTERO et al., 2005) - , sendo que alguns metais também fazem parte efetivamente dos seus compostos ativos (TANJI \& VALOPPI, 1989; LALAH; NJOGU; WANDIGA, 2009). Em Mato Grosso, com economia potencialmente agrícola, Viana (2006) detectou contaminações por metais pesados em área de agrossilvicultura, dentre as quais de destacam o Cr e o Zn, que são alguns dos produtos da decomposição de agrocorretivos e agrotóxicos. Ferro, manganês e alumínio foram detectados nas águas do SAB localizadas sob área de fertirrigação com vinhaça em usina sucroalcooleira no centro-oeste da região de São Paulo (HASSUDA; REBOUÇAS; CUNHA, 1990). Existem pelo menos 143 agroquímicos diferentes e 21 produtos de transformação que já foram encontrados solubilizados em águas subterrâneas (USGS, 1996).

A criação de bovinos em Mato Grosso do Sul também ocupa posição de destaque no mercado brasileiro e acabou atraindo investimentos em instalações de frigoríficos e curtumes na região. Nesse tipo de indústria, a maior preocupação é a contaminação por cromo, encontrado no lodo decorrente do processo de curtimento mineral do couro (SEBRAE, 2014). Na Índia (MONDAL \& SINGH, 2011; BRINDHA \& ELANGO, 2012), onde o couro representa um dos principais produtos de exportação do país, e no Paquistão (TARIQ et al., 2006), foram detectadas concentrações de cromo, decorrentes dos efluentes das indústrias de curtumes da região, nas águas subterrâneas.

Esses fatos incentivam o estudo da contaminação das águas subterrâneas, sendo que o conhecimento sobre os teores de metais presentes é de fundamental importância para que haja o controle e o monitoramento de sua qualidade. A dificuldade persiste em estabelecer se essas contribuições em meios aquosos são de fontes naturais ou de origem antrópica, pois, às vezes, as rochas possuem enriquecimento de determinados elementos químicos (BERTOLO et al., 2011a; 2011b) que resultam em concentrações de metal em níveis geralmente superiores aos "backgrounds" da região ou das diretrizes máximas estabelecidas por organizações de saúde. Por outro lado, o desenvolvimento industrial e urbano ou uso de pesticidas e fertilizantes na agricultura, por exemplo, são fontes antrópicas que podem causar o aumento de metais nas águas subterrâneas.

O SAB em Mato Grosso do Sul, aquífero poroso e livre, possui uma extensa área de afloramento (GOVERNO DO ESTADO DE MATO GROSSO DO SUL, 2010). Essas características o tornam mais vulnerável ao efeito desordenado da urbanização e das atividades econômicas do Estado. Considerando as principais fontes da economia do Estado, este estudo teve como objetivo a análise da concentração dos metais cobre $(\mathrm{Cu})$, cromo $(\mathrm{Cr})$, ferro $(\mathrm{Fe})$, manganês $(\mathrm{Mn})$ e zinco $(\mathrm{Zn})$ na água subterrânea visando auxiliar no estabelecimento de diretrizes para o gerenciamento do aquífero.

\section{MATERIAIS E MÉTODOS}

\section{Área de estudo}

O estudo abrangeu as águas subterrâneas do SAB compreendidas no Estado de Mato Grosso do Sul (Figura 1), cuja área de afloramento ocupa cerca de 37\% (GOVERNO DO ESTADO DE MATO GROSSO DO SUL, 2010) da área total de 357.145,532 $\mathrm{km}^{2}$ do Estado (IBGE, 2010).

O SAB é composto por rochas sedimentares de idade cretácea superior (GOVERNO DO ESTADO DE MATO GROSSO DO SUL, 2010), que compõem o último episódio significativo de deposição sobre a Bacia Sedimentar do Paraná. Essa sequência sedimentar em Mato Grosso do Sul é subdivida em dois Grupos: Grupo Bauru e Grupo Caiuá (CPRM et al., 2006). Tal divisão considera as Formações Marília e Vale do Rio do Peixe pertencendo ao Grupo Bauru e as Formações Santo Anastácio e Caiuá, ao Grupo Caiuá.

O Grupo Bauru é constituído por arenitos finos e mal selecionados na base e por arenitos argilosos e calcíferos no topo (CAMPOS, 2004). O Grupo Caiuá, por sua vez, é formado por arenitos de muito finos a finos, quartzosos, bem selecionados, com coloração de marrom-avermelhada a arroxeada, grãos com brilho fosco e películas de óxido de ferro e está assentado sobre os derrames basálticos da Formação Serra Geral (BATEZELLI, 2010).

As rochas do Grupo Bauru no Estado são representadas pelas Formações Marília e Vale do Rio do Peixe, na porção nordeste, enquanto para o Grupo Caiuá, predominando na região centro-sul, somente a Formação Santo Anastácio é definida (CPRM et al., 2006), ocorrendo, na região sudeste, rochas consideradas por Fernandes \& Branco (2015) como Grupo Caiuá indiviso.

Embora existam diferenças de sedimentação dessas formações, o Plano Estadual de Recursos Hídricos adotou, em termos hidrogeológicos, todo o pacote da Bacia Bauru como SAB (GOVERNO DO ESTADO DE MATO GROSSO DO SUL, 2010).

O modelo conceitual do Aquífero Bauru em Mato Grosso do Sul é baseado em estudo realizado pela Tahal, em 1998, que estabelece o sentido predominante do fluxo do Aquífero de oeste para leste. As cotas potenciométricas são da ordem de 650 a $600 \mathrm{~m}$ na região ocidental, próximo ao município de Campo Grande, diminuindo para até $250 \mathrm{~m}$ próximo à calha do Rio Paraná, a leste (CPRM, 2012). As linhas de fluxo do Aquífero tendem a manter a direção aos vales dos principais rios, como o Sucuriú, o Pardo e o Verde, 
os quais são abastecidos durante a maior parte do ano, e também em direção à calha do Rio Paraná (TAHAL \& SANESUL, 1998). Por ser um aquífero livre e poroso, predomina área de recarga em toda a sua área de afloramento.

O Aquífero Bauru é caracterizado predominantemente por águas bicarbonatadas, devido à composição mineralógica das rochas que o compõem, em especial devido à presença de carbonato de cálcio e argilominerais que aumentam a salinidade de suas águas (CAMPOS, 2004).

\section{Coleta de dados}

Os dados apresentados e analisados neste trabalho referem-se àqueles fornecidos pela Empresa de Saneamento do Estado de Mato Grosso do Sul S. A. (SANESUL) e pela Companhia de Pesquisa de Recursos Minerais (CPRM), sendo, portanto, dados secundários.

As coletas de amostras e as análises químicas das águas subterrâneas dos poços selecionados para o estudo foram realizadas pelas empresas citadas, durante suas rotinas anuais de controle de qualidade de água.

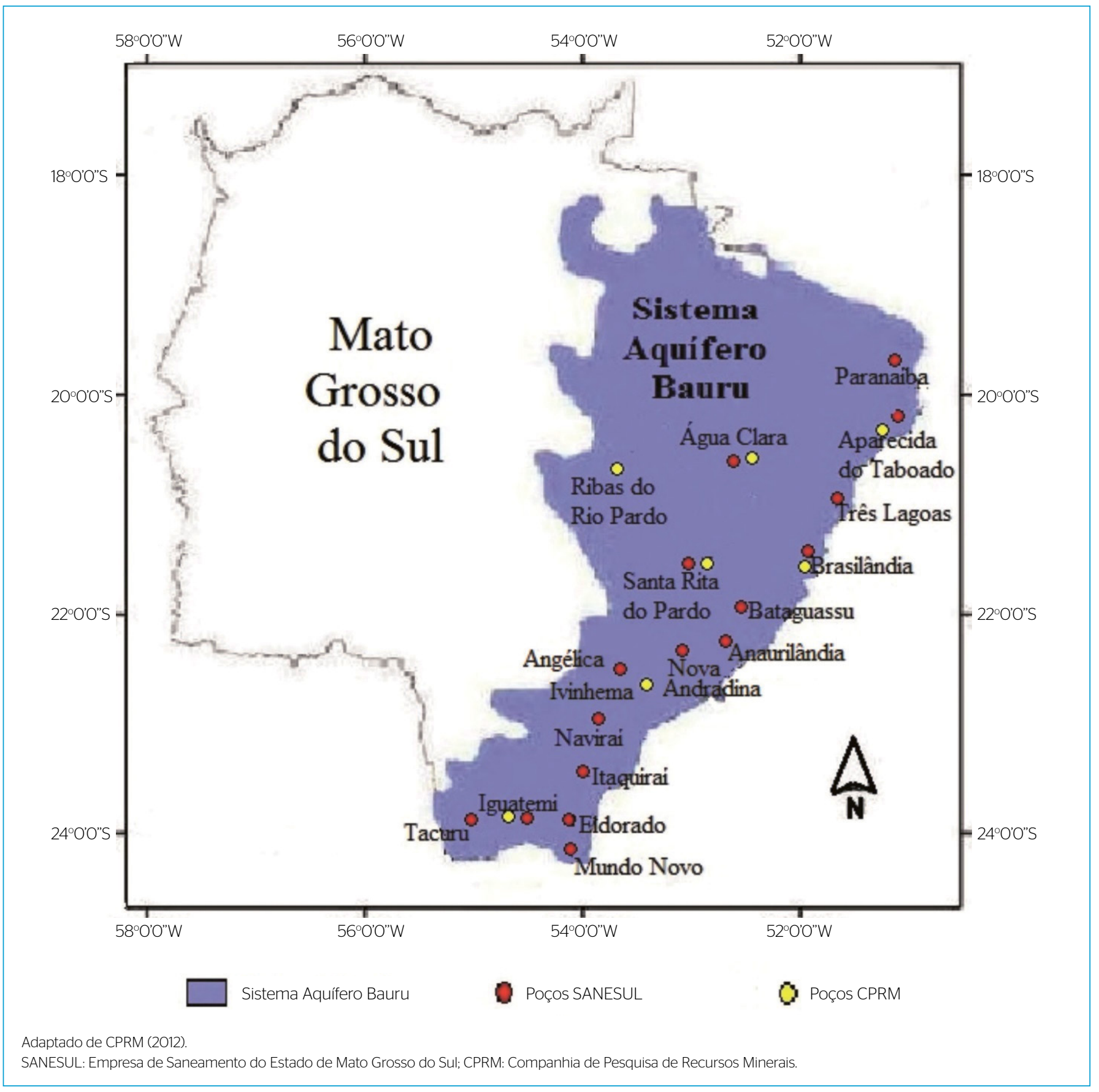

Figura 1 - Mapa com a localização do Sistema Aquífero Bauru em Mato Grosso do Sul com os municípios que possuem os poços tubulares analisados. 
Para os poços da SANESUL, a partir da análise dos perfis geológicos e construtivos dos poços cadastrados no banco de dados da empresa e de suas características hidrodinâmicas (nível estático e dinâmico, altimetria), foi selecionado pelo menos um poço em operação por município que capta água do $\mathrm{SAB}$, distribuídos em toda a sua extensão de afloramento no Estado. Assim, foram selecionados poços localizados nos municípios de Aparecida do Taboado, Paranaíba, Água Clara, Bataguassu, Brasilândia, Santa Rita do Pardo, Três Lagoas, Anaurilândia, Angélica, Nova Andradina, Eldorado, Iguatemi, Itaquiraí, Mundo Novo, Naviraí e Tacuru, todos em operação na área de estudo, do período de 2009 a 2013 (Figura 1). Na região norte do SAB não foram definidos poços para análise, pois a SANESUL não possui poços nessa região.

Em relação aos diferentes depósitos do $\mathrm{SAB}$, não foi possível efetuar a diferenciação destes, uma vez que os perfis dos poços não permitem a distinção das unidades litoestratigráficas como detalhado no Estado de São Paulo. Se considerarmos as rochas aflorantes, pode-se inferir que os poços da região nordeste da área de estudo captam água da Formação Vale do Rio do Peixe e, localmente, da Formação Marília; na região centro-sudeste, os poços explotam água da Formação Santo Anastácio.

A seleção dos parâmetros químicos estudados baseou-se em informações da literatura especializada em relação às atividades econômicas na área de estudo. Assim, foram selecionados os metais $\mathrm{Cu}, \mathrm{Cr}, \mathrm{Fe}, \mathrm{Mn}$ e Zn.

Para os poços da CPRM, foram obtidos os perfis geológicos construtivos e análises químicas de todos os poços de monitoramento que a companhia possui na região do SAB em Mato Grosso do Sul (Figura 1), dos períodos de 2012 e 2013, os quais possuem dados de análise química dos metais estudados e de parâmetros para a classificação hidroquímica. Por serem poços de monitoramento do aquífero pertencentes à Rede Integrada de Monitoramento das Águas (RIMAS), as coletas e análises são realizadas uma vez ao ano em período não determinado e possuem um maior detalhamento de informações, ao contrário da SANESUL, cujos poços são basicamente para abastecimento público.

Os parâmetros obtidos pela SANESUL foram determinados pelo Laboratório Central de Análises de Qualidade de Água da empresa, por espectrofotômetro de absorção atômica, sendo que os métodos empregados para a determinação dos metais seguiram os procedimentos da American Public Health Association (APHA, 2005); e as análises da CPRM foram efetuadas por espectrofotometria de emissão atômica com plasma indutivamente acoplado.

\section{Tratamento dos dados}

Os resultados das concentrações de $\mathrm{Cu}, \mathrm{Cr}$, Fe, Mn e Zn inferiores aos limites de detecção do método (LDM) analítico utilizado ou ao limite de quantificação da amostra (LQA) foram considerados iguais aos valores do LQA ou do LDM para compor a série de dados para o tratamento estatístico. Essa adequação foi espelhada no mesmo método utilizado pela Companhia de Tecnologia de Saneamento Ambiental (CETESB), do Estado de São Paulo, na elaboração dos seus relatórios trienais de qualidade de suas águas subterrâneas (CETESB, 2013).

\section{Análise de conformidade}

As concentrações de metais dos poços do $\mathrm{SAB}$ foram comparadas aos valores máximos permitidos (VMPs) de potabilidade e organolépticos para consumo humano presentes nas legislações brasileiras pertinentes: Portaria no 2.914/2011, do Ministério da Saúde, que trata sobre os procedimentos de controle e de vigilância da qualidade da água (BRASIL, 2011); Resolução Conselho Nacional do Meio Ambiente (CONAMA) 396/2008, que estabelece diretrizes para a classificação e o enquadramento das águas subterrâneas (CONAMA, 2008); e Resolução CONAMA no 420/2009, que trata do controle da qualidade do solo e estabelece o gerenciamento de áreas contaminadas (CONAMA, 2009).

Com os resultados das concentrações de Cr e Fe também foi realizado o enquadramento das águas do $\mathrm{SAB}$, pontualmente para cada poço em estudo, conforme a Resolução CONAMA nº 396/2008 (CONAMA, 2008), adotando-se como valor de referência de qualidade (VQRs) os VMPs de potabilidade e organolépticos para consumo humano presentes na legislação brasileira, Portaria n 2.914/2011, do Ministério da Saúde.

\section{Caracterização e classificação hidroquímica}

A caracterização e a classificação das águas subterrâneas foram realizadas a partir dos resultados das análises químicas preexistentes dos poços do SAB monitorados pela CPRM em Mato Grosso do Sul, referentes ao período de 2012 a 2013. Para tal atividade, foram elaborados Diagramas de Piper (FEITOSA \& MANOEL FILHO, 2008) com o auxílio do software livre Qualigraf (MÖBUS, 2009).

O valor da alcalinidade total foi convertido em concentrações de carbonato de alcalinidade (CO3-2) e bicarbonato de alcalinidade (HCO3-) para que estes pudessem ser inseridos com os valores de cloreto $(\mathrm{Cl}-)$, sulfato(SO4-2), sódio $(\mathrm{Na}+)$, potássio $(\mathrm{K}+)$, cálcio $(\mathrm{Ca} 2+) \mathrm{e}$ magnésio $(\mathrm{Mg} 2+)$ para obtenção do Diagrama d e Piper.

\section{Análise de possíveis fontes contaminantes}

Para avaliação do uso e ocupação da área de estudo, foi efetuada uma integração de dados a partir de mapa espacial do Projeto Sistema de Informação Geográfica do Agronegócio (SIGA), desenvolvido pela Associação dos Produtores de Soja (APROSOJA/MS) e lançado pela Federação de Agricultura e Pecuária de Mato Grosso do Sul (FAMASUL).

Para a análise das possíveis fontes poluidoras das águas subterrâneas, foram consultados materiais de referência a respeito de contaminação de aquíferos (livros, periódicos, revistas, anais, publicação eletrônica) e correlacionados com as atividades econômicas obtidas na etapa de levantamento do uso e ocupação da área. Adicionalmente, foram pesquisados estudos de casos de contaminação realizados em Mato Grosso do Sul. 


\section{RESULTADOS E DISCUSSÃO}

\section{Conformidade dos poços no Sistema Aquífero Bauru em Mato Grosso do Sul}

As concentrações de $\mathrm{Cu}, \mathrm{Cr}, \mathrm{Fe}, \mathrm{Mn}$ e Zn, de 2009 a 2013, correspondentes aos poços da SANESUL no SAB foram comparadas aos parâmetros de qualidade, segundo legislação vigente no país (Tabela 1).

Concentrações de $\mathrm{Cu}$ acima de 2,5 mg. $\mathrm{L}^{-1}$ deixam a água com gosto amargo (WHO, 2004). Ao observar a Tabela 1, nota-se que todos os poços analisados estão dentro do limite dos padrões de potabilidade para consumo humano $\left(2,0 \mathrm{mg} . \mathrm{L}^{-1}\right)$ no SAB.

A ingestão diária máxima de Cr via alimentação pode variar entre os países e seus limites máximos são estabelecidos basicamente em função do cromo hexavalente, altamente tóxico (CETESB, 2012a). Dentre todos os poços analisados, somente ITQ-002 (Itaquiraí) e ITQ-003 (Itaquiraí), em 2012, ultrapassaram o limite $\left(0,5 \mathrm{mg} . \mathrm{L}^{-1}\right)$, com valores que atingiram 5,0 mg. $\mathrm{L}^{-1}$. Como nos anos seguintes as concentrações desses poços reduziram para valores inferiores ao limite do padrão de potabilidade, não se consideram necessárias investigações para as alterações detectadas.

Dos dados analisados de 2009 a 2013, 5 poços apresentaram valores de Mn acima do permitido (0,1 mg..-1): PAR-004, em 2013 (Paranaíba); AGC-004 (Água Clara), de 2011 a 2013; TLG-015 (Três Lagoas), em 2009 e 2011; TLG-032 (Três Lagoas), em 2009 e 2012; e NVA-013 (Nova Andradina), em 2010 e 2012. Dentre esses poços, o PAR-004 (Paranaíba) e o AGC-004 (Água Clara) merecem um estudo mais detalhado, pois a concentração de manganês sofreu um aumento gradativo de 2009 até 2013. Analisando os perfis geológicos desses poços e de outros em seu entorno, não são descritos minerais de $\mathrm{Mn}$ em sua formação; a presença desse metal pode ser devida aos insumos agrícolas da agrossilvicultura em Água Clara, da soja e do cultivo de cana-de-açúcar em Paranaíba (BÖHLKE, 2002; CUTLER et al., 2013; MENEZES et al., 2014).

Em relação ao Fe, 7 poços encontram-se com o teor acima do VMP (0,3 mg. $\left.\mathrm{L}^{-1}\right)$, sendo que o poço BRA-003 (Brasilândia), em 2010 e 2013, e ITQ-003 (Itaquiraí), em 2012, atingiram um pico muito elevado com valores maior que $0,3 \mathrm{mg} \cdot \mathrm{L}^{-1}(>3,00 ; 1,43 \mathrm{e}$ 17,00 mg.L.-1, respectivamente). O ITQ-003 (Itaquiraí) teve seu valor reduzido, retornando aos padrões estabelecidos na Portaria $\mathrm{n}^{\circ}$ 2.914/2011 em 2013, mas o BRA-003 (Brasilândia) manteve seu nível elevado. Analisando os perfis geológicos desses poços e de outros em seu entorno, foi observada a presença de $\mathrm{Fe}_{2} \mathrm{O}_{3}$ na formação litológica do poço BRA-004, próximo ao BRA-003, em Brasilândia. Considera-se que as concentrações de Fe na água devem ser decorrentes da interação desta com minerais portadores do metal, nas fácies avermelhadas e ferruginosas descritas na literatura (MILANI et al., 2007; BATEZELLI, 2010).
Mesmo estando fora dos padrões organolépticos de potabilidade, as concentrações de Fe e Mn, com exceção do poço ITQ-003 (Itaquiraí), que apresentou teor de Fe de 17,00 mg.L $\mathrm{L}^{-1}$ em 2012 e retornou aos padrões estabelecidos na Portaria no 2.914/2011 em 2013, encontram-se inferiores a 2,4 e 0,4 mg. $\mathrm{L}^{-1}$, respectivamente, e os demais parâmetros analisados estão dentro dos padrões estabelecidos para os poços analisados. Esses são critérios previstos na Portaria 2.914/2011, do Ministério da Saúde, que, quando atendidos, permitem que os teores de Fe e Mn sejam superiores aos valores máximos permitidos previstos na norma.

O teor de Zn geralmente é mais elevado nas águas subterrâneas do que em superficiais (LOLLAR, 2005; CETESB, 2012b). O VMP para consumo humano é de 5,0 mg. $\mathrm{L}^{-1}$ nas legislações brasileiras e de 4,0 mg. $L^{-1}$ nos valores de referência da Organização Mundial de Saúde (OMS), considerando ambos os padrões organolépticos. A concentração de todos os pontos amostrados de 2009 a 2013 apresenta-se com grande margem de segurança em relação ao limite de potabilidade estabelecido considerando padrões organolépticos.

Os poços descritos na Tabela 1 são utilizados para abastecimento público local pela empresa SANESUL. Para o enquadramento do SAB em cada ponto analisado em Mato Grosso do Sul, considerando que o uso preponderante dessas águas é para consumo humano, os poços BRA-003 (Brasilândia) e MUN-002 (Mundo Novo) exigem tratamento para consumo humano com relação ao teor de Fe (superior a 0,03 mg. $\mathrm{L}^{-1}$ ), podendo ser enquadrados na Classe 2. Os demais poços analisados estão dentro dos padrões permitidos de potabilidade, não sofrendo alteração em sua qualidade que exija tratamento para o consumo humano, sendo, por isso, enquadrados na Classe 1.

\section{Caracterização do Sistema Aquífero Bauru}

A caracterização do SAB em Mato Grosso do Sul foi realizada pela mediana dos resultados dos principais parâmetros analisados nos sete poços monitorados e operados pela CPRM, no período de 2012 e 2013, conforme apresentado na Tabela 2.

As profundidades dos poços atingem um valor médio de $60 \mathrm{~m}$ e abrangem integralmente as rochas sedimentares que compõem o Aquífero Bauru.

Os valores do $\mathrm{pH}$ das amostras variaram de 5,01 a 7,27, com valor médio de 6,14, sendo que, em geral, apresentaram característica levemente ácida das águas. Tais valores são inferiores aos relatados para o aquífero no Estado de São Paulo, de 4,08 a 10,97, com valor médio de 7,06 (BARISON \& CHANG, 2002). Tais variações podem ser decorrentes dos tipos faciológicos da Bacia Bauru (FERNANDES \& BRANCO, 2015).

Com base no Diagrama de Piper (Figura 2), observa-se que nos poços SR01 (Santa Rita do Pardo), RB01 (Ribas do Rio Pardo), AC01 (Água Clara) e IV01 (Ivinhema) predominam as águas bicarbonatadas cálcicas. O poço BR01 (Brasilândia) possui águas bicarbonatadas magnesianas. O poço AT01 (Aparecida do Taboado) apresenta águas bicarbonatadas sódicas. 


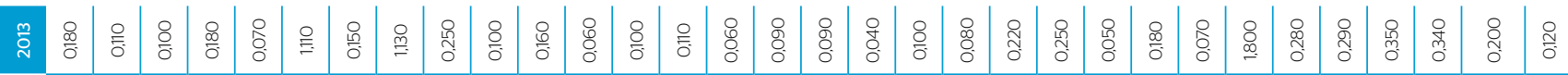

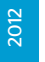

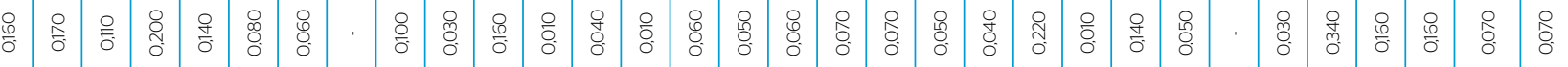
宗 영

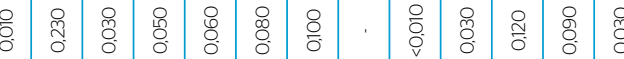

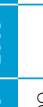

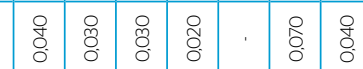
흔 要

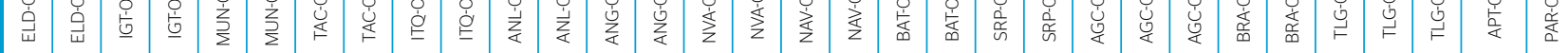

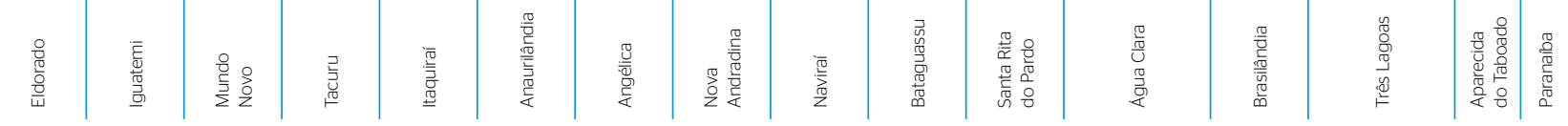


Tabela 2 - Medianas dos principais parâmetros hidroquímicos nos poços monitorados pela Companhia de Pesquisa de Recursos Minerais no Sistema Aquífero Bauru em Mato Grosso do Sul, do período de 2012 a 2013.

\begin{tabular}{|c|c|c|c|c|c|c|c|c|c|c|c|c|c|c|}
\hline \multirow{2}{*}{ Município } & \multirow{2}{*}{ Poço } & \multirow{2}{*}{$\begin{array}{l}\text { Prof. } \\
(\mathrm{m})\end{array}$} & \multirow{2}{*}{$\mathrm{pH}$} & \multirow{2}{*}{$\begin{array}{c}\text { Alcalinidade } \\
\text { total }\left(\mathrm{CaCo}_{3}\right. \\
\mathrm{mg} \cdot \mathrm{L}-1)\end{array}$} & \multicolumn{10}{|c|}{ (mg.L-1) } \\
\hline & & & & & $\mathrm{Ca}$ & $\mathrm{Mg}$ & $\mathrm{Cl}$ & K & $\mathrm{Na}$ & $\mathrm{NO}_{3}$ & $\mathrm{SO}_{4}$ & $\mathrm{HCO}_{3}$ & $\mathrm{CO}_{3}$ & $\mathrm{PO}_{4}$ \\
\hline Iguatemi & IGO1 & 60,00 & 5,010 & 4,065 & 1,950 & 0,853 & 4,510 & 2,055 & 11,400 & 42,294 & $<0,100$ & 4,959 & 2,439 & $<0,400$ \\
\hline Ivinhema & IVO1 & 52,00 & 5,560 & 2,840 & 1,051 & 0,240 & 0,648 & 0,296 & 0,430 & 0,411 & $<0,100$ & 3,465 & 1,704 & $<0,400$ \\
\hline Brasilândia & BRO1 & 60,00 & 5,635 & 1,600 & 0,325 & 0,121 & 0,024 & 0,334 & 0,056 & 0,070 & $<0,100$ & 1,952 & 0,960 & $<0,400$ \\
\hline Água Clara & ACO1 & 58,00 & 5,825 & 3,630 & 1,325 & 0,192 & 0,041 & 0,467 & 0,640 & 0,849 & $<0,100$ & 4,429 & 2,178 & $<0,400$ \\
\hline Ribas do Rio Pardo & RBO1 & 58,00 & 6,015 & 3,375 & 0,775 & 0,123 & 0,010 & 0,252 & 0,081 & 0,111 & $<0,100$ & 4,118 & 2,025 & $<0,400$ \\
\hline
\end{tabular}

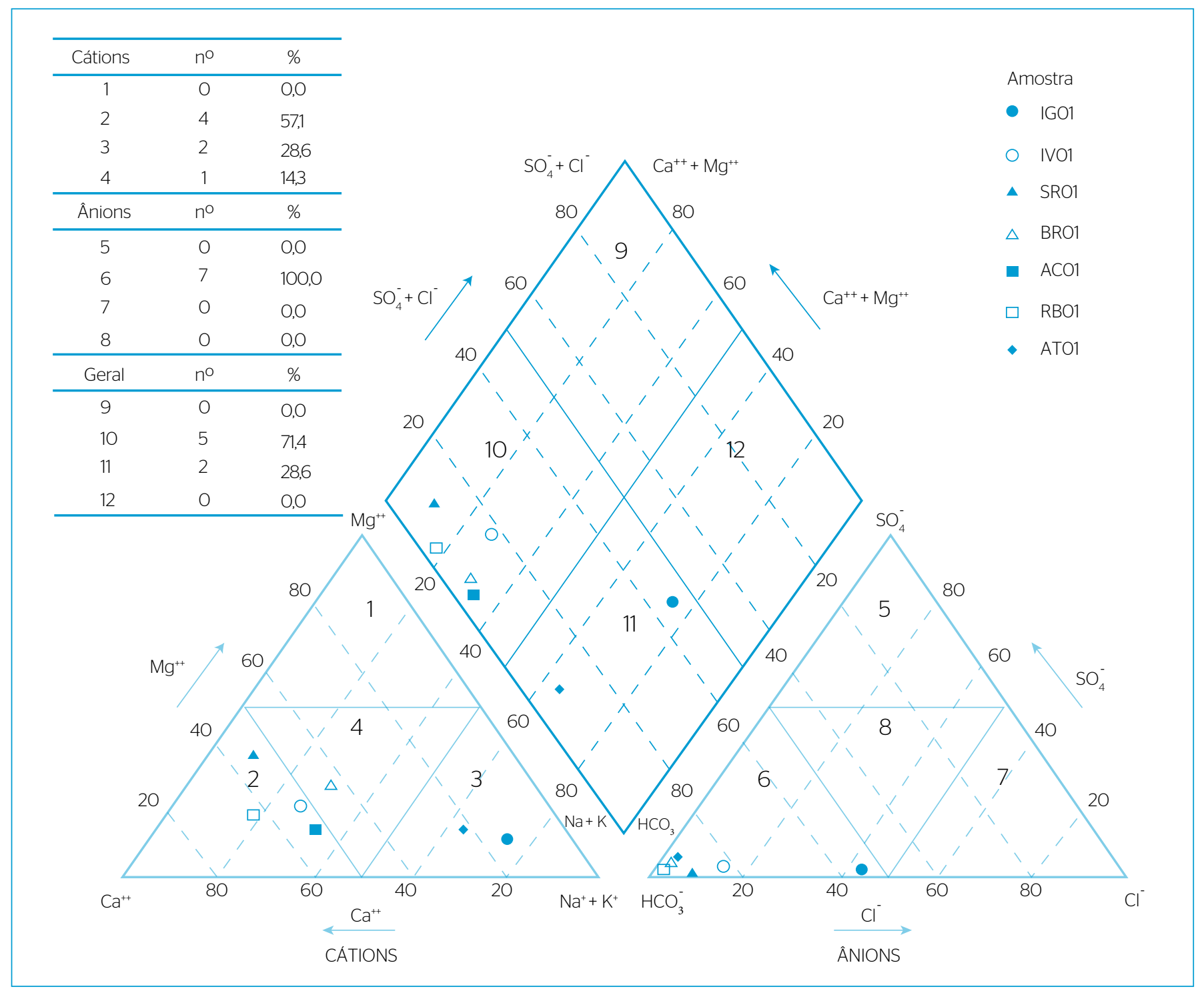

Figura 2 - Diagrama de Piper das medianas das amostras dos poços da Companhia de Pesquisa de Recursos Minerais no Sistema Aquífero Bauru em Mato Grosso do Sul. 
As águas dos poços monitorados pela CPRM no SAB de Mato Grosso do Sul, em sua maioria (71,5\%), são bicarbonatas cálcicas, e secundariamente bicarbonatadas sódicas. A predominância dessa fácie hidroquímica no Aquífero Bauru foi descrita por alguns autores no Estado de São Paulo (ROCHA et al., 1982; BARISON \& CHANG, 2002, 2004; CAMPOS, 2004; SILVA \& CHANG, 2010; CHANG; STRADIOTO; PAULA E SILVA, 2012). Os mesmos autores classificam as águas do Aquífero como fracamente bicarbonatadas e cálcio-magnesianas, sendo que localmente é considerada como bicarbonatada sódica. Rocha et al. (1982) descrevem a presença de águas bicarbonatadas sódicas em área do sudoeste paulista, entre os Rios do Peixe e Santo Anastácio. A mineralização das águas com sódio é descrita localmente nas cidades de Araçatuba e Presidente Prudente (BARISON \& CHANG, 2002, 2004). Silva \& Chang (2012) relatam a presença, embora em menor quantidade, de águas cloretadas sódicas no sudoeste paulista.

Em termos geoquímicos, a mineralização de cálcio, que define a predominância das águas bicarbonatadas cálcicas, pode ser associada aos arenitos calcíferos e ao cimento carbonático das Formações Marília e Vale do Rio do Peixe, pertencentes ao Grupo Bauru (FERNANDES \& COIMBRA, 2000; CPRM et al., 2006).

Os valores da alcalinidade total foram caracterizados principalmente pela presença de bicarbonatos, com todas as amostras apresentando $\mathrm{pH}$ inferior a 8,3. O poço de Santa Rita do Pardo apresentou a maior discrepância na concentração da alcalinidade total, com média de 50,0 mg. $\mathrm{L}^{-1} \mathrm{CaCO}_{3}$. Os demais poços não ultrapassaram $10 \mathrm{mg} \cdot \mathrm{L}^{-1} \mathrm{CaCO}_{3}$.

\section{Possíveis fontes de contaminação em Mato Grosso do Sul}

A contaminação da água subterrânea tem preocupado a sociedade, pois mesmo o solo tendo a capacidade de imobilização de grande parte dos poluentes, essa habilidade é limitada. As principais fontes poluidoras dos aquíferos se concentram nas atividades domésticas (matéria orgânica e micro-organismos patogênicos), industriais (componentes químicos, metais e elementos radioativos), agrícolas (fertilizantes e defensivos agrícolas) e de exploração de reservas minerais (CONCEIÇÃO et al., 2009).

Em Mato Grosso do Sul, as principais atividades produtivas com potencial de contaminação da água subterrânea são os curtumes/frigoríficos, as usinas sucroalcooleiras, as plantações de cana-de-açúcar e soja e as indústrias de celulose. Na área de afloramento do $\mathrm{SAB}$ no Estado praticamente não se tem atividade de mineração.Com o deslocamento dos grandes rebanhos bovinos para a Região Centro-Oeste do país, muitos frigoríficos e curtumes passaram a se instalar próximos a seus centros fornecedores. No Estado de Mato Grosso do Sul, a poluição por Cr decorre principalmente do processo de curtimento do couro. Até 2006, havia 11 curtumes ativos em Mato Grosso do Sul, onde a maioria produz apenas o couro wet blue, que é o estágio inicial do processamento do couro (FREITAS, 2006). Destes, cinco encontram-se sobre a região do $\mathrm{SAB}$, distribuídos entre os municípios de Naviraí, Três Lagoas, Nova Andradina, Iguatemi e Paranaíba (FREITAS, 2006). Entretanto, muitos frigoríficos instalados no Estado também passaram a beneficiar o couro cru, processando-os até a etapa do wet blue, como ocorre no frigorífico localizado em Bataguassu. Até abril de 2012, 35 frigoríficos registrados no Sistema de Inspeção Federal (SIF) foram instalados em Mato Grosso do Sul (Figura 3), dos quais 25 se encontram em operação e se distribuem por 19 municípios do Estado (MASCARENHAS; RUI; CARLOTTO, 2012); destes, 10 encontram-se sobre a região do $\mathrm{SAB}$, distribuídos entre os municípios de Naviraí, Bataguassu, Paranaíba, Aparecida do Taboado, Cassilândia, Iguatemi e Nova Andradina (MASCARENHAS; RUI; CARLOTTO, 2012).

Freitas (2006) realizou estudos utilizando técnicas de absorção atômica e colorimetria e verificou que o único tipo de Cr presente nos efluentes de três curtumes avaliados e localizados em Mato Grosso do Sul é o Cr III, não sendo detectado o Cr VI. Contudo, a maioria das amostras analisadas estava acima dos limites estabelecidos na legislação.

Desde 2008, o Brasil é considerado o terceiro maior produtor mundial de alimentos, mas também se tornou o maior consumidor de agrotóxicos (SCHLESINGER, 2013). Embora alguns estudos mostrem que os elementos que compõem os agrotóxicos utilizados na agricultura são encontrados em baixas concentrações nas águas subterrâneas, existem elementos com alta mobilidade no solo que são carreados até os aquíferos (DORES \& DE-LAMONICA-FREIRE, 2001; STEFFEN; STEFFEN; ANTONIOLLI, 2011).

A cana-de-açúcar é um dos maiores consumidores de herbicida do país (ARMAS et al., 2005), sendo constatada como a possível fonte de contaminação das águas subterrâneas em estudo realizado nos municípios de Cosmópolis e Santa Bárbara d'Oeste, em São Paulo (LUIZ; NEVES; DYNIA, 2004). Além disso, usinas de álcool e açúcar estão entre as cadeias produtivas que têm avançado muito nos últimos anos em Mato Grosso do Sul, que possuía, até 2014, cerca de 24 usinas sucroalcooleiras, segundo a Associação dos Produtores de Bioenergia de Mato Grosso do Sul (BIOSUL, 2016), distribuídas principalmente nas regiões leste e sul do Estado (Figura 4), onde afloram tanto o Aquífero Bauru como o Serra Geral, respectivamente, tornando importante o monitoramento da qualidade do solo e dos recursos hídricos da região, além do destino dado à vinhaça resultante dos processos industriais das usinas sucroalcooleiras. Estudos sobre a qualidade de águas subterrâneas em área com uso da vinhaça em fertirrigação no cultivo 
de cana-de-açúcar, entre 2009 a 2012, em uma usina de Mato Grosso do Sul, indicaram que a qualidade das águas subterrâneas está sendo influenciada pela vinhaça aplicada na cana-de-açúcar (OLIVEIRA et al., 2013).

Entre os poluentes da indústria de papel e celulose, é possível encontrar concentrações de metais pesados nos efluentes dos processos de produção (REACH FOR UNBLEACHED, 1997 apud MOLINA; PARREIRA; FERNANDES JR., 2004). O mesmo ocorre com o Cr, que geralmente é utilizado no tratamento da madeira (ASMUS, 1999 apud FREITAS, 2006).
A indústria de papel e celulose foi a que provocou maior impacto na economia sul mato-grossense nos últimos anos. O Estado de Mato Grosso do Sul apresentou, em 2010, o maior aumento percentual na prática da silvicultura, com $27,4 \%$, tornando-se o $4^{\circ}$ maior produtor de florestas do país, com uma área aproximada de 388 mil hectares (ABRAF, 2011 apud CHAEBO et al. 2011). Entretanto, não foram encontrados estudos relacionados a possíveis contaminações provenientes da indústria de papel e celulose, na região de Mato Grosso do Sul, decorrentes de compostos constituídos por metais pesados utilizados nos processos industriais.

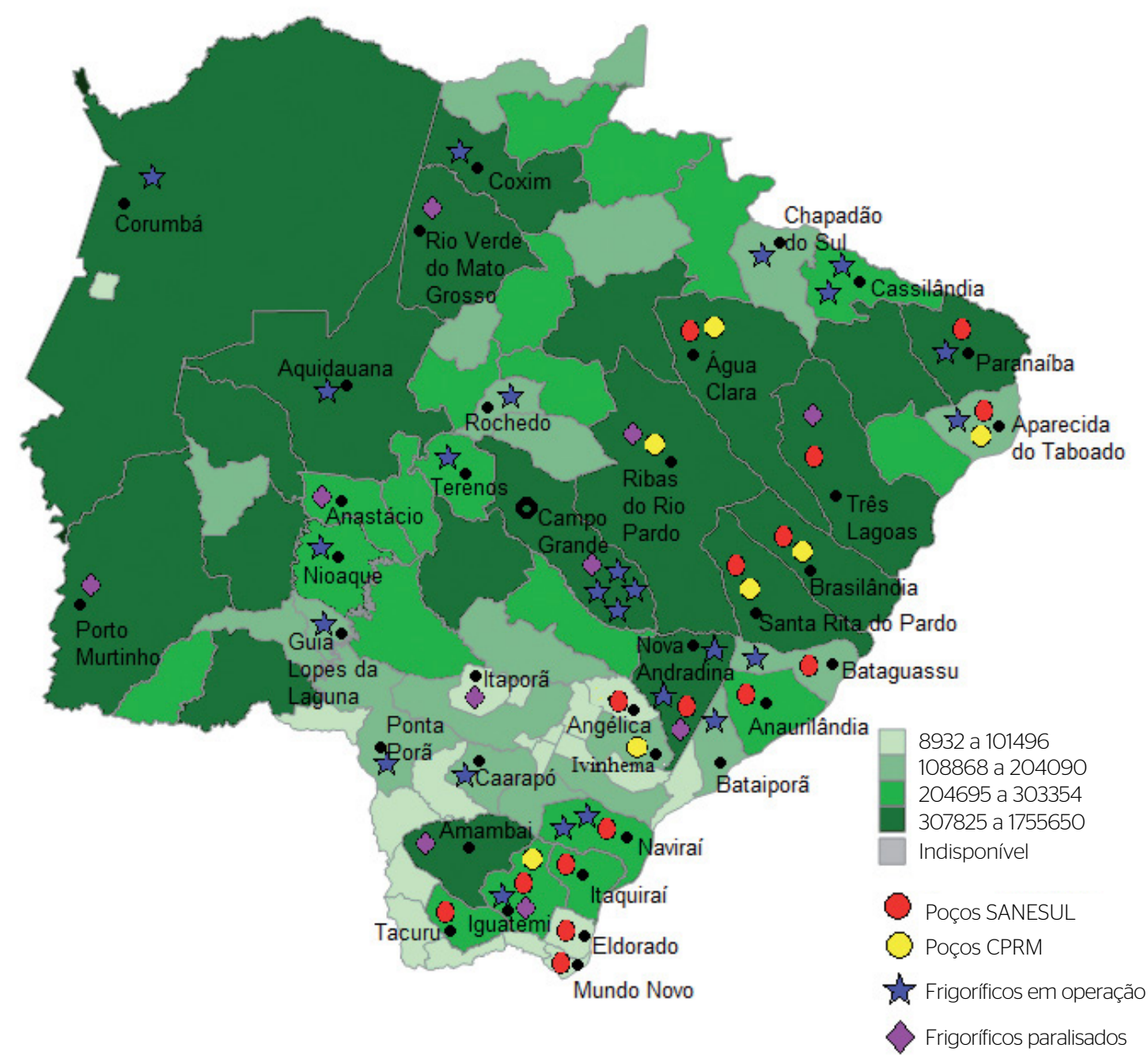

Adaptado de SFA/MS - Dados do Sistema de Inspeção Federal citado por Mascarenhas, Rui e Carlotto (2012) e IBGE (2014a).

SANESUL: Empresa de Saneamento do Estado de Mato Grosso do Sul; CPRM: Companhia de Pesquisa de Recursos Minerais.

Figura 3 - Distribuição espacial do efetivo do rebanho bovino, por cabeça, no Mato Grosso do Sul, em 2012 e espacialização dos frigoríficos de bovinos com Sistema de Inspeção Federal em Mato Grosso do Sul. 


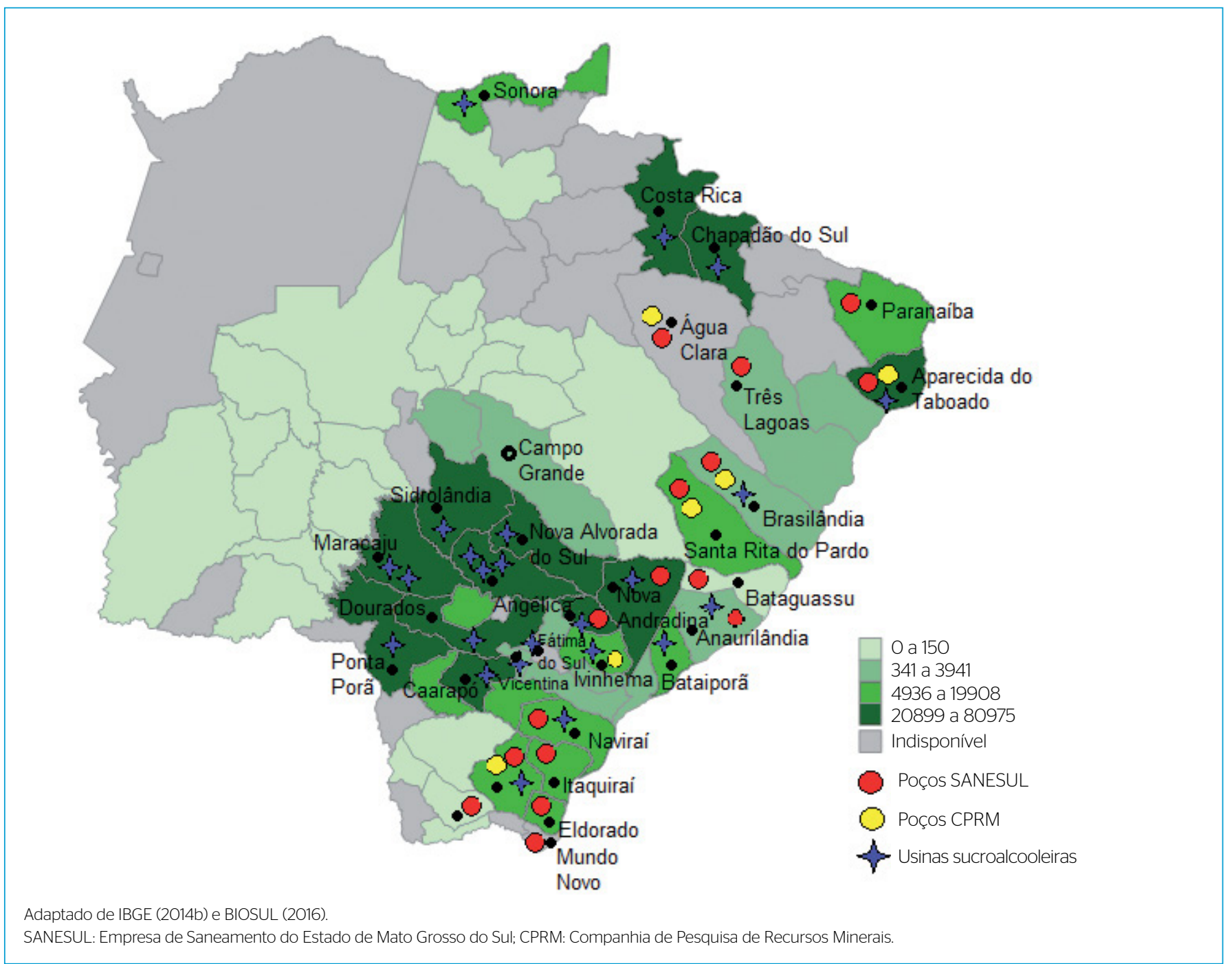

Figura 4 - Distribuição espacial das áreas cultivadas, em hectares, com cana-de-açúcar no Mato Grosso do Sul, em 2012, e espacialização das usinas sucroalcooleiras, em 2014.

\section{CONCLUSÃO}

Foram analisadas as concentrações de $\mathrm{Cu}, \mathrm{Cr}, \mathrm{Fe}, \mathrm{Mn}$ e $\mathrm{Zn}$ na água subterrânea de 32 poços localizados no SAB, em Mato Grosso do Sul, referentes ao período de 2009 a 2013.

Em geral, as concentrações de $\mathrm{Cu}, \mathrm{Cr}$ e $\mathrm{Zn}$, no período analisado, não sofreram alterações e mantiveram-se dentro dos limites de potabilidade estabelecidos na legislação. O Mn e o Fe apresentaram, em alguns poços, valores fora dos padrões organolépticos de potabilidade; contudo, esses valores atendem a critérios específicos previstos na Portaria n 2.914/2011, do Ministério da Saúde (BRASIL, 2011), que permitem que os teores desses elementos sejam superiores aos valores máximos permitidos previstos na norma.

Os poços analisados estão dentro dos padrões permitidos de potabilidade, não sofrendo alteração em sua qualidade que exija tratamento para o consumo humano, enquadrando-se na Classe 1; com exceção dos poços BRA-003 (Brasilândia) e MUN-002 (Mundo Novo), que estão acima do VMP para ferro, exigindo tratamento diferenciado para consumo humano, podendo ser enquadrados na Classe 2.

Há a tendência predominante de águas bicarbonatadas cálcicas no Aquífero Bauru, confirmando dados da literatura no SAB da Bacia do Paraná.

A qualidade das águas subterrâneas do SAB em Mato Grosso do Sul pode ser influenciada pelas atividades antrópicas, como os herbicidas, a vinhaça aplicada como fertilizante no cultivo da cana-de-açúcar e o Cr total, decorrente principalmente do processo de curtimento do couro, em que o Cr III foi detectado acima dos limites estabelecidos na legislação em três curtumes estudados.

Não foram encontrados estudos relacionados a possíveis contaminações por metais provenientes da indústria de papel e celulose, no Estado de Mato Grosso do Sul. 
É importante o monitoramento da qualidade das águas do SAB não só dos metais aqui estudados, mas de todos os parâmetros físico-químicos e bacteriológicos necessários para o estabelecimento de diretrizes de gerenciamento desse aquífero. Considera-se, adicionalmente, a importância de um estudo de vulnerabilidade do aquífero ao risco de contaminação, uma vez que se trata de um aquífero poroso e livre e com grande importância para o abastecimento público e privado.

\section{REFERÊNCIAS}

AMERICAN PUBLIC HEALTH ASSOCIATION - APHA. (2005) Standard Methods for the Examination of Water and Wastewater. 21st ed. Washington: APHA.

ARMAS, E.D.; MONTEIRO, R.T.R.; AMÂNCIO, A.V.; CORREA, R.M.L.; GUERCIO, M.A. (2005) Uso de agrotóxicos em cana-de-açúcar na Bacia do Rio Corumbataí e o risco de poluição hídrica. Química Nova, v. 28, n. 6, p. 975-985.

ASSOCIAÇÃO BRASILEIRA DE BIOENERGIA DE MATO GROSSO DO SUL - BIOSUL. (2016) Mapa da Bioenergia: Mato Grosso do Sul (safra 14-15). Sem escala. Disponível em: < http://www.biosulms. com.br/bioenergia>. Acesso em: 04 ago. 2016.

BAILEY, S.E.; OLIN, T.J.; BRICKA, R.M.; ADRIAN, D.D. (1999) A review of potentially low-cost sorbents for heavy metals. Water Research, v. 33, n. 11, p. 2469-2479.

BARISON, M.R. \& CHANG, K.H. (2002) Caracterização hidroquímica da porção meridional do Aquífero Bauru no estado de São Paulo. In: CONGRESSO BRASILEIRO DE AGUAS SUBTERRÂNEAS, 12. Florianópolis. Anais... Florianópolis: ABAS. 12p.

BARISON, M.R.\&CHANG, K.H.(2004)Parâmetros hidrogeoquímicos regionais do Sistema Aquífero Bauru no Estado de São Paulo. In: CONGRESSO BRASILEIRO DE ÁGUAS SUBTERRÂNEAS, 13. Cuiabá. Anais... Cuiabá: ABAS. 22p.

BATEZELLI, A. (2010) Arcabouço tectono-estratigráfico e evolução das Bacias Caiuá e Bauru no sudeste brasileiro. Revista Brasileira de Geociência, v. 40, n. 2, p. 265-285.

BERTOLO, R.; BOUROTTE, C.; MARCOLAN, L.; OLIVEIRA, S.; HIRATA, R. (2011a) Anomalous content of chromium in a Cretaceous sandstone Aquifer of the Bauru Basin, State of São Paulo, Brazil. Journal of South American Earth Sciences, v. 31, n. 1, p. 69-80.

BERTOLO, R.; BOUROTTE, C.; HIRATA, R.; MARCOLAN, L.; SRACEK, $\mathrm{O}$. (2011b) Geochemistry of natural chromium occurrence in a sandstone Aquifer in Bauru Basin, São Paulo State, Brazil. Applied Geochemistry, v. 26, n. 8, p. 1353-1363.

BRASIL. Ministério da Saúde - MS. (2011) Portaria n 2914, de 12 de dezembro de 2011. Dispõe sobre os procedimentos de controle e de vigilância da qualidade da água para consumo humano e seu padrão de potabilidade. Brasília.

BÖHLKE, J-K. (2002) Groundwater recharge and agricultural contamination. Hydrogeology Journal, v. 10, p. 153-179.
BRINDHA, K. \& ELANGO, L. (2012) Impact of Tanning Industries on Groundwater Quality near a Metropolitan City in India. Water Resources Management, v. 26, n. 6, p. 1747-1761.

CAMPOS, H.C.N.S. (2004) Águas subterrâneas na Bacia do Paraná Geosul, v. 19, n. 37, p. 47-65.

CHAEBO, G.; NETO, N.F.; CAMPEÃO, P.; NORILLER, R.M.; LUCENA, R.M. de (2011). Silvicultura em Mato Grosso do Sul: Desafios e perspectivas a formação de um arranjo produtivo local. Revista de Administração da UEG, v. 2, n. 2, p. 23-39.

CHANG, K.H.; STRADIOTO, M.R.; PAULA E SILVA, F. de (2012) Hidroquímica do Sistema Aquífero Bauru na região sudoeste do Estado de São Paulo. In: CONGRESSO BRASILEIRO DE ÁGUAS SUBTERRÂNEAS, 17. EENCONTRO NACIONAL DE PERFURADORES DE POÇOS, 18. Bonito. Anais... Bonito: ABAS. 4p.

COMPANHIA AMBIENTAL DO ESTADO DE SÃO PAULO - CETESB. (2012a) Ficha de Informação Toxicológica - Crômio e seus compostos. São Paulo: CETESB.

COMPANHIA AMBIENTAL DO ESTADO DE SÃO PAULO - CETESB. (2012b) Ficha de Informação Toxicológica - Zinco. São Paulo: CETESB.

COMPANHIA AMBIENTAL DO ESTADO DE SÃO PAULO - CETESB. (2013) Relatório de qualidade das águas subterrâneas no Estado de São Paulo 2010-2012 (Série Relatórios). São Paulo: CETESB.

COMPANHIA DE PESQUISA E RECURSOS MINERAIS - CPRM; DEPARTAMENTO DE ÁGUAS E ENERGIA ELÉTRICA - DAEE; INSTITUTO GEOLÓGICO - IG; INSTITUTO DE PESQUISAS TECNOLÓGICA - IPT. (2006) Mapa geológico do Estado de Mato Grosso do Sul (escala 1:1.000.000). São Paulo: CPRM/DAEE/IG/IPT.

COMPANHIA DE PESQUISA E RECURSOS MINERAIS - CPRM. (2012) Rede Integrada de Monitoramento das Águas Subterrâneas: relatório diagnóstico Sistema Aquífero Bauru-Caiuá nos Estados de São Paulo, Mato Grosso do Sul e Paraná. Belo Horizonte: CPRM. (Volume 14)

CONCEIÇÃO, F.T.; CUNHA, R.; SARDINHA, D.S.; SOUZA, A.D.G.; SINELLI, O. (2009) Hidrogeoquímica do Aquífero Guarani na área urbana de ribeirão preto (SP). Geociências, v. 28, n. 1, p. 65-77.

CONSELHO NACIONAL DO MEIO AMBIENTE - CONAMA. (2008) Resolução $n^{\circ}$ 396: Dispõe sobre a classificação e diretrizes ambientais para o enquadramento das águas subterrâneas e dá outras providências. Brasília: CONAMA. 
CONSELHO NACIONAL DO MEIO AMBIENTE - CONAMA. (2009) Resolução $n^{\circ}$ 42O: Dispõe sobre critérios e valores orientadores de qualidade do solo quanto à presença de substâncias químicas e estabelece diretrizes para o gerenciamento ambiental de áreas contaminadas por essas substâncias em decorrência de atividades antrópicas. Brasilia: CONAMA.

CUTLER, W.G.; BREWER, R.C.; EL-KADI, A.; HUE, N.V.; NIEMEYER, P.G.; PEARD, J.; RAY, C. (2013) Bioaccessible arsenic in soils of former sugar cane plantations, Island of Hawaii. Science of the Total Environment, v. 442, p. 177-188.

DORES, E.F.G.C. \& DE-LAMONICA-FREIRE, E.M. (2001) Contaminação do ambiente aquático por pesticidas. estudo de caso: águas usadas para consumo humano em Primavera do Leste, Mato Grosso Análise Preliminar. Química Nova, v. 24, n. 1, p. 27-36.

FEITOSA, F.A.C. \& MANOEL FILHO, J. (Coord.) (2008) Hidrogeologia: conceitos e aplicações. 3a ed. Fortaleza: CPRM, LABHID-UFPE.

FERNANDES, L.A. \& COIMBRA, A.M. (2000) Revisão estratigráfica da parte oriental da Bacia Bauru (Neocretáceo). Revista Brasileira de Geociências, v. 30, n. 4, p. 717-728.

FERNANDES, L.A. \& BRANCO, H.C. (2015) Calcretes neocretácicos da Formação Marilia, Bacia Bauru. In: DIAS-BRITO, D. \& TIBANA, P. Calcários do Cretáceo do Brasil: um atlas. Rio Claro: Unesp-IGCE-UNES-Petro, p.481-496.

FREITAS, T.C.M. (2006) O cromo na indústria de curtumes de Mato Grosso do Sul, Brasil: aspectos ecológicos. Tese (Doutorado em Ciências da Saúde) - Programa Multi-institucional de PósGraduação em Ciências da Saúde - Rede Centro-Oeste, Convênio Universidade de Brasília, Universidade Federal de Goiás e Universidade Federal de Mato Grosso do Sul, Campo Grande.

GOVERNO DO ESTADO DE MATO GROSSO DO SUL. Secretaria de Estado de Meio Ambiente, do Planejamento, da Ciência e Tecnologia. (2010) Plano estadual de recursos hídricos de Mato Grosso do Sul. Campo Grande: Editora UEMS.

HASSUDA, S.; REBOUÇAS, A.C.; CUNHA, R.C.A. (1990) Aspectos qualitativos da infiltração da vinhaça de cana no Aquífero Bauru. Revista IG, v. 11, n. 2, p. 5-20.

INSTITUTO BRASILEIRO DE GEOGRAFIA E ESTATISTICA - IBGE. (2010) Censo Demográfico 2010 - Estados. Brasília. Disponível em: <http://www.ibge.gov.br/estadosat/>. Acesso em: 28 jul. 2012.

INSTITUTO BRASILEIRO DE GEOGRAFIA E ESTATISTICA - IBGE. (2014a) Cidades (Mato Grosso do Sul) - 2012. Mapa pecuária: bovinos - efetivo dos rebanhos (cabeças). Sem escala. Disponível em: <http://cod.ibge.gov.br/1CPGE>. Acesso em: 08 abr. 2014.

INSTITUTO BRASILEIRO DE GEOGRAFIA E ESTATISTICA - IBGE. (2014b) Cidades (Mato Grosso do Sul) - 2012. Mapa lavoura temporária: cana-de-açúcar - área plantada (hectares). Sem escala. Disponível em: <http://cod.bge.gov.br/1CPHQ>. Acesso em: 08 abr. 2014.

LALAH, J.O.; NJOGU, S.N.; WANDIGA, S.O. (2009) The Effects of $\mathrm{Mn2}+, \mathrm{Ni2}+, \mathrm{Cu} 2+, \mathrm{Co} 2+$ and $\mathrm{Zn2}+$ lons on Pesticide Adsorption and Mobility in a Tropical Soil. Bulletin of Environmental Contamination and Toxicology, v. 83, n. 3, p. 352-358.
LOLLAR, B.S. (2005) Environmental Geochemistry. Oxford: ELSEVIER.

LUIZ, A.J.B.; NEVES, M.C.; DYNIA, J.F. (2004) Implicações potenciais na qualidade das águas subterrâneas das atividades agrícolas na Região Metropolitana de Campinas, SP. Jaguariúna: EMBRAPA. (Boletim de Pesquisa e Desenvolvimento 25).

MASCARENHAS, A.; RUI, A.; CARLOTTO, L. (2012) Participação de mercado das indústrias frigoríficas em Mato Grosso do Sul. Campo Grande: Famasul.

MENEZES, J.P.C:; BERTOSSI, A.P.A.; SANTOS, A.R.; NEVES, M.A. (2O14) Correlação entre uso da terra e qualidade da água subterrânea. Engenharia Sanitária e Ambiental, v. 19, n. 2, p. 173-186.

MILANI, E.J; MELO, J.H.G.; SOUZA, P.A.; FERNANDES, L.A.; FRANÇA, A.B.B. (2007) Bacia do Paraná. Boletim de Geociências da Petrobras, v. 15, n. 2, p. 265-287.

MÖBUS, G. (2009) Qualigraf: software para interpretação de análises físicas. Fortaleza: Fundação Cearense de Meteorologia e Recursos Hídricos.

MOLINA, C.E.C.; PARREIRA, A.B.; FERNANDES JR., J.L. (2004) Comportamento mecânico de misturas de resíduo da fabricação de papel e solo para utilização na construção rodoviária. In: Congresso de Pesquisa e Ensino em Transportes, 18. Florianópolis. Anais... Florianópolis: ANPET, p. 247-258.

MONDAL, N.C. \& SINGH, V.P. (2O11) Hydrochemical analysis of salinization for a tannery belt in Southern India. Journal of Hydrology, v. 405, n. 3-4, p. 235-47.

OLIVEIRA, A.C.C.; CARVALHO, L.A.; SÚAREZ, Y.R.; NOVAK, E. (2O13) Análise de atributos físicos, químicos e microbiológicos de poços de monitoramento em área de fertirrigação. In: CONGRESSO INTERNACIONAL DE MEIO AMBIENTE SUBTERRÂNEO, 3. São Paulo. Anais... São Paulo: ABAS, 4 p.

OTERO, N.; VITORIA, L.; SOLER, A.; CANALS, A. (2005) Fertiliser characterisation: Major, trace and rare earth elements. Applied Geochemistry, v. 2O, p. 1473-1488.

ROCHA, G.A.; BERTACHINI, A.C.; CAMPOS, C.N.S.; CAIXETA, J.B. (1982) Tentativa de zoneamento das características hidráulicas e hidroquímicas do Aquífero Bauru. In: ENCONTRO DE GEOLOGIA E HIDROGEOLOGIA: O GRUPO BAURU NO ESTADO DE SÃO PAULO, 1. São Paulo. Publicação Especial... São Paulo: SBG/ABAS. 2Op.

SCHLESINGER, S. Dois casos sérios em Mato Grosso: a soja em Lucas do Rio Verde e a cana-de-açúcar em Barra do Bugres. 1a ed. Mato Grosso: FORMAD, 2013.

SERVIÇO BRASILEIRO DE APOIO ASS MICRO E PEQUENAS EMPRESAS - SEBRAE. (2014) Como montar uma empresa de curtume. Disponível em: <http://www.sebrae.com.br/sites/PortalSebrae/ideias/como-montaruma-empresa-de-curtume,b5887a51b9105410VgnVCM1000003b740 10aRCRD >. Acesso em: 23 mar. 2014.

SILVA, S.R. \& CHANG, H.K. (2010) Hidroquímica dos sistemas Aquíferos Bauru e Guarani na região metropolitana de Bauru (SP). Aguas Subterrâneas, v. 24, n. 1, p. 69-84. 
STEFFEN, G.P.K.; STEFFEN, R.B.; ANTONIOLLI, Z.I. (2011). Contaminação do Solo e da Água Pelo Uso de Agrotóxicos. Tecnológica, v. 15, n. 1, p. 15-21.

TAHAL CONSULTING ENGINEERS LTD; EMPRESA DE SANEAMENTO DE MATO GROSSO DO SUL S.A. - SANESUL. (1998) Estudos Hidrogeológicos de Mato Grosso do Sul - Relatório Final. Campo Grande. 736 p.

TANJI, K. \& VALOPPI, L. (1989) Groundwater contamination by trace elements. Agriculture, Ecosystems and Environment, v. 26, n. 3-4, p. $229-74$.

TARIQ, S.R.; SHAH, M.H.; SHAHEEN, N.; KHALIQUE, A.; MANZOOR, S.; JAFFAR, M. (2006) Multivariate analysis of trace metal levels in tannery effluents in relation to soil and water: A case study from Peshawar, Pakistan. Journal of Environmental Management, v. 79, n. 1, p. 20-9.
UNITED STATES GEOLOGICAL SURVEY - USGS. (1996) Pesticides in ground water - current understanding of distribution and major influences. Disponível em: <http://pubs.usgs.gov/fs/1995/0244/ report.pdf>. Acesso em: 06 out. 2014.

VIANA, V.M.F.C. (2006) Estudo Hidrogeoquímico das Veredas do Rio do Formoso no Município de Buritizeiro, Minas Gerais. Dissertação (Mestrado em Geologia) - Universidade Federal de Minas Gerais, Belo Horizonte.

WORLD HEALTH ORGANIZATION - WHO. (2004) Copper in drinking-water: background document for the development of WHO guidelines for drinking-water. Geneva: WHO.

WORLD HEALTH ORGANIZATION - WHO. (2011) Guidelines for drinking-water quality. 4th ed. Geneva: WHO. 